\title{
Revisiting Fat-Tailed Uncertainty in the Economics of Climate Change
}

\section{Citation}

Weitzman, Marin L. 2011. Revisiting Fat-tailed uncertainty in the economics of climate change. Review of Environmental Economics and Policy 5(2): 275-292.

\section{Published Version}

doi:10.1093/reep/rer006

\section{Permanent link}

http://nrs.harvard.edu/urn-3:HUL.InstRepos:11130443

\section{Terms of Use}

This article was downloaded from Harvard University's DASH repository, and is made available under the terms and conditions applicable to Open Access Policy Articles, as set forth at http:// nrs.harvard.edu/urn-3:HUL.InstRepos:dash.current.terms-of-use\#OAP

\section{Share Your Story}

The Harvard community has made this article openly available.

Please share how this access benefits you. Submit a story.

\section{Accessibility}




\title{
Revisiting Fat-Tailed Uncertainty in the Economics of Climate Change
}

\author{
Martin L. Weitzman* \\ August 23, 2010. REEP Symposium on Fat Tails.
}

\begin{abstract}
In this paper I revisit some basic issues concerning structural uncertainty and catastrophic climate change. My target audience here is general economists, so this paper could also be viewed as a somewhat less technical exposition supplementing my previous work. I argue by example that it is implausible that low-probability high-negative-impact events would not much influence an economic analysis of climate change. I try to integrate the empirical examples and the theory together into a unified package with a unified message.
\end{abstract}

\section{Introduction}

I believe that the most striking feature of the economics of climate change is that its extreme downside is non-negligible. Deep structural uncertainty about the unknown unknowns of what might go very wrong is coupled with essentially unlimited downside liability on possible planetary damages. This is a recipe for producing fat tails in the extremes of critical probability distributions. There is a battle being waged in the bad fat tail between declining probabilities and increasing damages that is very difficult to resolve because it is so far outside the realm of ordinary experience. No one knows what exactly to do about this disturbing situation. One thing is for sure: it does not make economic analysis of climate change any easier.

\footnotetext{
*(mweitzman@harvard.edu) Without blaming them for the remaining deficiencies in this paper, I am extremely grateful for the constructive comments on an earlier version by James Annan, Daniel Cole, Stephen DeCanio, Baruch Fischoff, Don Fullerton, John Harte, William Hogan, David Kelly, Michael Oppenheimer, Robert Pindyck, Joseph Romm, and Richard Tol.
} 
In this paper I address some criticisms that have been leveled at previous work of mine on fat tails and the so-called "dismal theorem." At first I was inclined to debate some of the critics and their criticisms more directly. But on second thought I found myself anxious not to be drawn, by so doing, into being too defensive and having the main focus be on technical details. Instead, I am more keen here to emphasize anew and in fresh language the substantive concepts that, I think, may be more obscured than enlightened by a debate centered on technicalities. I am far more committed to the simple basic ideas that underlie this approach than I am to the particular mathematical form in which I have chosen to express them. These core concepts could have been wrapped in a variety of alternative mathematical shells - and the particular one that I chose previously is somewhat arbitrary. The implications are roughly similar, irrespective of formalization. Some technical details are unavoidable, but if I can make the underlying concepts acquire greater intuitive plausibility, then I believe that this set of ideas will become more self-evident and more self-evidently resistant to several of the criticisms that have been leveled against it.

In the following section 2, I present an intuitive-empirical argument that deep structural uncertainty lies at the heart of climate change economics. Then, in section 3 , I try to explain some of the theory behind fat-tailed extreme events and discuss some possible implications for the analysis of climate change. Section 4 concludes with a few summary remarks.

\section{Deep Structural Uncertainty about Climate Extremes}

By benefit-cost analysis (BCA) of climate change, I mean, in the widest sense, some overall economic analysis centered on maximizing (or at least comparing) welfare. My notion of BCA in the present context is so broad that it overlaps with an integrated assessment model (IAM), and here I treat the two as essentially interchangeable. I begin by setting up a straw man that I will label the "standard BCA of climate change." Of course there is no "standard BCA of climate change," but I think this is an allowable simplification for purposes of exposition here.

In this section I try to make a heuristic-empirical case for there being big structural uncertainties in the economics of extreme climate change. I will argue on intuitive grounds that the way in which this deep uncertainty is conceptualized and formalized should influence the outcomes of any reasonable BCA of climate change. Further, I will argue that the idea that uncertainty about extremes does not substantially influence outcomes from the "standard" BCA is implausible. My arguments in this section are not intended to be airtight or rigorous. Rather, this is an intuitive presentation based on some very rough stylized facts. 
We all know that computer-driven simulations are dependent upon the core assumptions of the model inside the computer. My intuitive examples are frankly aimed at sowing a few seeds of doubt that the "standard BCA of climate change" is fairly representing structural uncertainties about extreme events, and therefore its conclusions might be less robust than is commonly acknowledged. I do not say that the "standard BCA of climate change" is wrong or even implausible, so much as that it is not robust with respect to the modeling of catastrophic outcomes. I will try to make my case by citing five aspects of the climate science and economics that do not seem to me to be adequately captured by the standard BCA. The five examples - which I call "Exhibits 1, 2, 3, 4 and 5" - are limited to structural uncertainty concerning the modeling of climate disasters. While other important aspects of structural uncertainty might also be cited, I restrict my stylized facts to these five examples. In the spirit of performing a kind of a "stress test" on the standard BCA, I naturally concentrate on things that might go wrong rather than things that might go right.

"Exhibit 1" concerns the atmospheric level of greenhouse gases (GHGs) over the last 800,000 years. Ice core drilling in Antarctica began in the late 1970s and is still ongoing. The record of carbon dioxide $\left(\mathrm{CO}_{2}\right)$ and methane $\left(\mathrm{CH}_{4}\right)$ trapped in tiny ice-core bubbles currently spans 800,000 years. $^{1} \quad$ It is important to recognize that the numbers in this unparalleled 800,000-year record of GHG levels are among the very best data that exist in the science of paleoclimate. Almost all other data (including past temperatures) are inferred indirectly from proxy variables, whereas these ice-core GHG data are directly observed.

The pre-industrial-revolution level of atmospheric $\mathrm{CO}_{2}$ (about two centuries ago) was 280 parts per million (ppm). The ice-core data show that $\mathrm{CO}_{2}$ varied gradually during the last 800,000 years within a relatively narrow range roughly between 180 and $280 \mathrm{ppm}$ and has never been above $300 \mathrm{ppm}$. Currently, $\mathrm{CO}_{2}$ is at about $390 \mathrm{ppm}$, and climbing steeply. Methane was never higher than 750 parts per billion (ppb) in 800,000 years, but now this extremely potent GHG, which is 22 times more powerful than $\mathrm{CO}_{2}$ (per century), is at $1,780 \mathrm{ppb}$. The sum total of all carbon-dioxide-equivalent $\left(\mathrm{CO}_{2} \mathrm{e}\right)$ GHGs is currently at about $440 \mathrm{ppm}$. An even more startling contrast with the 800,000-year record is the rate of change of GHGs: increases in $\mathrm{CO}_{2}$ were below (and typically well below) 25 ppm within any past sub-period of 1,000 years, while now $\mathrm{CO}_{2}$ has risen by $25 \mathrm{ppm}$ in just the last 10 years. Thus, anthropogenic activity has elevated atmospheric $\mathrm{CO}_{2}$ and $\mathrm{CH}_{4}$ to levels far outside their natural range at a very rapid rate. The unprecedented scale and speed of GHG increases brings us into uncharted territory and makes predictions of future climate change very uncertain. L Looking ahead a century or two, the levels of atmospheric GHGs

\footnotetext{
${ }^{1}$ See Dieter et al (2008), from which my numbers are taken (supplemented by data from the Keeling curve for more recent times, available online at: ftp://ftp.cmdl.noaa.gov/ccg/co2/trends/co2_mm_mlo.txt).
} 
that may ultimately be attained (unless decisive measures are undertaken) have likely not existed for tens of millions of years and the speed of this change may be unique on a time scale of hundreds of millions of years.

Remarkably, the "standard BCA of climate change" takes little account of the magnitude of the uncertainties involved in extrapolating future climate change so far beyond past experience. Perhaps even more surprising, the gradual tightening of GHG emissions, which emerges as optimal policy from the "standard" BCA, typically attains stabilization at levels of $\mathrm{CO}_{2}$ that approach $700 \mathrm{ppm}$. The "standard" BCA thus recommends subjecting the Earth's system to an unprecedented shock from geologically-instantaneously jolting atmospheric stocks of GHGs up to two and a half times above their highest level over the last 800,000 years - without mentioning the unprecedented nature of this unique planetary experiment. This is my Exhibit 1.

"Exhibit 2" concerns the highly uncertain climate-change response to such kind of unprecedented increases in GHGs. For specificity, I focus on the uncertainty of so called "equilibrium climate sensitivity." This is a good example of a "known unknown." However, it should be understood that under the rubric of climate sensitivity I am trying to aggregate together an entire suite of uncertainties, including some non-negligible unknown unknowns. So "equilibrium climate sensitivity" is to be understood here as a prototype example of uncertainty, or a metaphor, which is being used to illustrate much more generic issues about highly uncertain climate change.

"Equilibrium climate sensitivity" (hereafter denoted $S$ ) is a key macro-indicator of the eventual temperature response to GHG changes. The Intergovernmental Panel on Climate Change in its IPCC-AR4 (2007) Executive Summary explains $S$ this way: "The equilibrium climate sensitivity is a measure of the climate system response to sustained radiative forcing. It is not a projection but is defined as the global average surface warming following a doubling of carbon dioxide concentrations. It is likely to be in the range 2 to $4.5^{\circ} \mathrm{C}$ with a best estimate of $3^{\circ} \mathrm{C}$, and is very unlikely to be less than $1.5^{\circ} \mathrm{C}$. Values substantially higher than $4.5^{\circ} \mathrm{C}$ cannot be excluded, but agreement of models with observations is not as good for those values." The actual empirical reason why these upper tails are long and seem heavy with probability dovetails with the theory: inductive knowledge is always useful, of course, but simultaneously it is limited in what it can tell us about extreme events outside the range of experience. In such situations one is forced back onto depending more than one might wish upon the prior probability density function $(\mathrm{PDF})$, which of necessity is largely subjective and relatively diffuse.

Any curve fitting exercise attempting to attribute probabilities to $\mathrm{S} \geq 4.5^{\circ} \mathrm{C}$, such as $\mathrm{I}$ am doing here, is little more than conjectural speculation. My purpose is merely to show that 
critical results can depend on seemingly casual decisions about how to model tail probabilities. To illustrate some striking implications for the analysis of climate change, I contrast the use of two familiar PDFs to represent the upper-half tail of climate sensitivity above the median: (1) the Pareto (or Power) distribution, subscripted $\mathbf{P}$, which is the prototype example of a fat upper tail; (2) the Normal distribution, subscripted $\mathbf{N}$, which is the prototype of a thin upper tail. There is some wiggle room in the definition of what constitutes a fat-tailed PDF or a thin-tailed PDF, but everyone agrees that probabilities declining exponentially or faster (like the Normal) are thin tailed while probabilities declining polynomially or slower (like the Pareto) are fat tailed. The IPCC defines "likely" as a probability above $66 \%$ but below $90 \%$. Here I choose $70 \%$ as defining "likely" and I calibrate all upper-tail probability distributions so that $\mathrm{P}\left[S \geq 3^{\circ} \mathrm{C}\right]=.5$, and $\mathrm{P}\left[S \geq 4.5^{\circ} \mathrm{C}\right]=.15 .^{2}$

The following table gives some values for the two cumulative distributions.

\begin{tabular}{|l|l|l|l|l|l|l|l|l|l|}
\hline$\widehat{S}=$ & $3^{\circ} \mathrm{C}$ & $4.5^{\circ} \mathrm{C}$ & $6^{\circ} \mathrm{C}$ & $8^{\circ} \mathrm{C}$ & $10^{\circ} \mathrm{C}$ & $12^{\circ} \mathrm{C}$ & $15^{\circ} \mathrm{C}$ & $18^{\circ} \mathrm{C}$ & $20^{\circ} \mathrm{C}$ \\
\hline$P_{\mathbf{P}}[S \geq \widehat{S}]$ & .5 & .15 & .06 & .027 & .014 & .008 & .004 & .003 & .002 \\
\hline$P_{\mathbf{N}}[S \geq \widehat{S}]$ & .5 & .15 & .02 & .003 & $7 \times 10^{-7}$ & $3 \times 10^{-10}$ & $6 \times 10^{-17}$ & $2 \times 10^{-25}$ & $4 \times 10^{-32}$ \\
\hline
\end{tabular}

Table 1: $\mathrm{P}[S \geq \widehat{S}]$ for a fat-tailed Pareto and thin-tailed Normal PDF.

Table 1 illustrates a tremendous difference in upper tail behavior. I think that the Pareto PDF of climate sensitivity has a disturbingly large amount of probability in its upper tail. There is no consensus on how to aggregate into one overarching PDF the results of many different climate sensitivity studies, and much controversy about how it might be done. For what it is worth (perhaps very little), the median upper five percent probability level over all 22 climate-sensitivity PDFs cited in IPCC-AR4 is $6.4^{\circ} \mathrm{C}$, which fits with the Pareto PDF above. $^{3}$ Table 1 is giving probabilities for climate sensitivity, which corresponds to GHG levels of $560 \mathrm{ppm}$ of $\mathrm{CO}_{2} \mathrm{e}$. Higher values of GHG concentrations give correspondingly higher probabilities of large temperatures responses, in proportion to the log of GHG concentrations.

Table 2 below calculates some values of steady-state probabilities of increased temperatures $\mathrm{T}$ as a function of GHG concentrations $\mathrm{G}$. The first row represents steady state atmospheric stocks of greenhouse gas concentrations $\mathrm{G}$ (measured in ppm of $\mathrm{CO}_{2} \mathrm{e}$ ). The second row below it gives the median equilibrium temperature $T_{\mathbf{M}}$ as a function of stabilized

\footnotetext{
${ }^{2}$ I lean more toward $\mathrm{P}\left[S \geq 4.5^{\circ} \mathrm{C}\right] \leq 17 \%$ than toward $\mathrm{P}\left[S \geq 4.5^{\circ} \mathrm{C}\right] \geq 5 \%$ because, for a time horizon of a century and a half or so, it is plausibly the more inclusive "earth system sensitivity" (which includes slow feedbacks like albedo changes or methane releases) that matters more than the "fast-feedback equilibrium sensitivity" that IPCC-AR4 refers to.

${ }^{3}$ Details in Weitzman (2009).
} 
GHG stocks. The remaining rows give the probabilities of achieving at least the steady state temperature increase represented by the entries in the table $\left(6^{\circ} \mathrm{C}\right.$ and $\left.10^{\circ} \mathrm{C}\right)$ for both of the chosen PDFs (Pareto $=\mathbf{P}=$ fat tail, Normal $=\mathbf{N}=$ thin tail $)$.

\begin{tabular}{|l|l|l|l|l|l|l|l|l|l|l|l|}
\hline G: & $\mathbf{4 0 0}$ & $\mathbf{4 5 0}$ & $\mathbf{5 0 0}$ & $\mathbf{5 5 0}$ & $\mathbf{6 0 0}$ & $\mathbf{6 5 0}$ & $\mathbf{7 0 0}$ & $\mathbf{7 5 0}$ & $\mathbf{8 0 0}$ & $\mathbf{9 0 0}$ & $\mathbf{1 0 0 0}$ \\
\hline \hline $\mathrm{T}_{\mathbf{M}}$ & $1.5^{\circ}$ & $2.1^{\circ}$ & $2.5^{\circ}$ & $2.9^{\circ}$ & $3.3^{\circ}$ & $3.6^{\circ}$ & $4.0^{\circ}$ & $4.3^{\circ}$ & $4.5^{\circ}$ & $5.1^{\circ}$ & $5.5^{\circ}$ \\
\hline \hline $\mathrm{P}_{\mathbf{P}}[\mathrm{T} \geq 6]$ & $.9 \%$ & $2 \%$ & $4 \%$ & $6 \%$ & $8 \%$ & $11 \%$ & $15 \%$ & $18 \%$ & $22 \%$ & $30 \%$ & $39 \%$ \\
\hline $\mathrm{P}_{\mathbf{N}}[\mathrm{T} \geq 6]$ & $10^{-9}$ & $10^{-5}$ & $.2 \%$ & $1 \%$ & $4 \%$ & $9 \%$ & $14 \%$ & $20 \%$ & $25 \%$ & $35 \%$ & $43 \%$ \\
\hline \hline $\mathrm{P}_{\mathbf{P}}[\mathrm{T} \geq 10]$ & $.2 \%$ & $.45 \%$ & $.8 \%$ & $1.3 \%$ & $1.9 \%$ & $2.5 \%$ & $3.2 \%$ & $4.0 \%$ & $4.8 \%$ & $6.6 \%$ & $8.5 \%$ \\
\hline $\mathrm{P}_{\mathbf{N}}[\mathrm{T} \geq 10]$ & $10^{-30}$ & $10^{-15}$ & $10^{-10}$ & $10^{-7}$ & $10^{-5}$ & $10^{-4}$ & $.1 \%$ & $.27 \%$ & $.64 \%$ & $2.1 \%$ & $4.6 \%$ \\
\hline
\end{tabular}

Table 2: Probabilities of exceeding $\mathrm{T}=6{ }^{\circ} \mathrm{C}$ and $\mathrm{T}=10{ }^{\circ} \mathrm{C}$ for given $\mathrm{G}=$ ppm of $\mathrm{CO}_{2} \mathrm{e}$.

What is especially striking to me in Table 2 is the reactiveness of high-temperature probabilities to the level of GHGs. The fat-tailed case seems especially worrisome. One implication is that an optimal policy might be expected to keep down GHG levels and be much less casual than the "standard" BCA about letting $\mathrm{CO}_{2}$ levels approach 700 ppm. I believe that Table 2 could be taken as indirect evidence that the main purpose of keeping down GHG concentrations is effectively to buy insurance against catastrophic global warming. The above examples of the highly uncertain climate-change response to unprecedented increases in GHGs constitutes my Exhibit 2.

"Exhibit 3" concerns possibly disastrous releases over the long run of bad-feedback components of the carbon cycle that are currently omitted from most general circulation models. The chief worry here is a significant supplementary component that conceptually should be added on to the so-called "fast feedback" climate sensitivity $S$ that IPCC-AR4 works with. This omitted component (which would be part of a more inclusive slow-feedback generalization called "earth system sensitivity") includes the powerful self-amplification potential of greenhouse warming due to heat-induced releases of sequestered carbon. One vivid example is the huge volume of GHGs currently trapped in tundra permafrost and other boggy soils (mostly as methane, a particularly potent GHG). A more remote (but even more vivid) possibility, which in principle should also be included, is heat-induced releases of the evenvaster offshore deposits of $\mathrm{CH}_{4}$ trapped in the form of clathrates - which has a very small, but decidedly non-zero, probability over the long run of having destabilized methane seep into the atmosphere if water temperatures over the continental shelves warm just slightly. 
The amount of $\mathrm{CH}_{4}$ involved is huge, although it is not precisely known. Most estimates place the carbon-equivalent content of methane hydrate deposits at about the same order of magnitude as all fossil fuels combined. Over the long run, a $\mathrm{CH}_{4}$ outgassing-amplifier process could potentially precipitate a disastrous strong-positive-feedback warming. Thus, while it is a low-probability event, the possibility of a climate meltdown is not just the outcome of a mathematical theory but has a real physical basis. ${ }^{4}$ Other examples of an actual physical basis for catastrophic outcomes could be cited, but this one will do here. This is my Exhibit 3.

"Exhibit 4" concerns what I view as a somewhat cavalier treatment in the literature of damages or disutilities from extreme temperature changes. The "standard" BCA damages function reduces welfare-equivalent output by a quadratic-polynomial multiplier of the form $M(T)=\alpha T^{2} /\left(1+\alpha T^{2}\right) . \quad$ I hasten to add that such calibrations were intended by the authors to capture low-temperature damages and were never intended to be extrapolated to very high temperature changes. For the sake of concreteness, I will use the damages function in the latest version of the well known DICE model of William Nordhaus (2008). ${ }^{5}$ The results in terms of relative damages to output are given as $Q(T)$ in Table 2 .

\begin{tabular}{|l|l|l|l|l|l|l|l|l|}
\hline$T$ & $2^{\circ} \mathrm{C}$ & $4^{\circ} \mathrm{C}$ & $6^{\circ} \mathrm{C}$ & $8^{\circ} \mathrm{C}$ & $10^{\circ} \mathrm{C}$ & $12^{\circ} \mathrm{C}$ & $15^{\circ} \mathrm{C}$ & $20^{\circ} \mathrm{C}$ \\
\hline$Q(T)$ & $1 \%$ & $4 \%$ & $8 \%$ & $13 \%$ & $19 \%$ & $26 \%$ & $35 \%$ & $49 \%$ \\
\hline
\end{tabular}

Table 3: Quadratic damages function $Q(T)=\alpha T^{2} /\left(1+\alpha T^{2}\right)$ with $\alpha=.002388$.

I do not find such numbers convincing for higher temperatures. At an extraordinarily high global average temperature change of $T=20^{\circ}$, the welfare-equivalent global consumption loss in Table 3 is "only" $49 \%$. The implied welfare-equivalent consumption losses of $35 \%$ for $T=15^{\circ}$, and $19 \%$ for $T=10^{\circ}$ also seem to me to be far too low for doing a serious analysis of the consequences of catastrophic losses from extreme climate change. Such a mild damages function is preordained to make extreme climate change look empirically negligible, almost no matter what else is assumed. Conversely, it turns out, fat-tailed PDFs are not by themselves sufficient to make extreme climate change have empirical "bite" without a damages function that is immiserising for high temperature changes.

So what should the damages function be for very high temperatures? No one knows, of

\footnotetext{
${ }^{4}$ For more about methane clathrates, see Archer (2007) and the recent article by Shakova et al (2010).

${ }^{5}$ Nordhaus's DICE model is perhaps the most famous integrated assessment model (IAM) in the economics of climate change. The value $\alpha=.002388$ was used to generate his Figure 3-3 on page 51 . Nordhaus wisely does not try to project beyond $T=6^{\circ}$, which is suitable for his purposes but unsatisfactory for mine.
} 
course. The predominant approach attempts to calculate what the world would be like for a given small increase in global average temperatures. The economist tries to quantify such things as damages due to changes in agricultural productivity, changes in climate, changes in life styles, rising oceans, and so forth. This is a constructive approach that probably represents the best we can do for small temperature changes. But I am uneasy when this philosophy is extended to large changes in global average temperatures. Taking the most extreme example I can imagine for making my point, suppose for the sake of argument that average global temperatures were to increase by the extraordinary amount of $10^{\circ} \mathrm{C}$ (with an extraordinarily low probability, of course). It is true that people live very well in places where the mean temperature is $10^{\circ} \mathrm{C}$ higher than in Yakutsk, Siberia. However, I do not think that these kinds of analogies can justify using such a comparative-geography approach for estimating welfare-equivalent damages from an average planetary temperature change of $10^{\circ} \mathrm{C}$. A "damages function" is a reduced form representing global welfare losses from global average temperatures, which incorporates a staggering amount of regional and seasonal weather heterogeneity. There is just too much structural uncertainty to put meaningful bounds on the unprecedented almost-unimaginable changes to planetary welfare from average global temperatures increasing by $10^{\circ} \mathrm{C}$. When there is such big uncertainty about catastrophic damages, and when the damages function for high temperature changes is so conjectural, the relevant degree of risk aversion, yet another important unknown here, will tend to play a significant role in economic analysis of climate change. Other things being equal, high degrees of risk aversion will make it more attractive to effectively take out insurance against uncertain extreme damages by keeping GHG emissions low.

Of course I have no objective way to determine magnitudes of high-temperature damages, but the last time that the world witnessed periods where global average temperatures were very roughly $\approx 10^{\circ} \mathrm{C}$ or so above the present was during the Eocene epoch $\approx 55-34$ mya. During these warming periods the earth was ice free while palm trees and alligators lived near the North Pole. The Eocene was also the last epoch in which there were geologically rapid increases in mean global temperatures of magnitude very roughly $\approx 5^{\circ} \mathrm{C}$ or so above an already warm background. Such hyperthermal events occurred over an average period of very roughly $\approx 100 \mathrm{~K}$ years or so, which is extremely gradual compared with current worstcase anthropogenically-induced trajectories. It is unknown what exactly triggered these temperature spikes, but they were accompanied by atmospheric carbon spikes. One leading culprit is the strong-feedback release of large amounts of methane hydrates from clathrate deposits, which is a non-negligible possibility over the next century or two if current emissions trends are extrapolated. The major point here is that relatively rapid changes of global average temperatures $\approx 5^{\circ} \mathrm{C}$ above present values are extremely rare events extraordinarily 
far outside the scope of human experience. As for huge temperature increases like $T \approx 10^{\circ}$, the planetary effects are difficult to imagine. To find a geologically instantaneous increase in temperatures of magnitude $T \approx 10^{\circ}$, one would perhaps have to go back hundreds of millions of years. Others are free to calibrate any welfare-equivalent consumption loss they want in the range above $T \approx 4^{\circ}$, as anybody's guess here is as good as mine. I don't think that a person needs accurate specific stories about what might happen for $T>10^{\circ}$ to imagine truly upending catastrophes undoing the planet and severely undermining the security of human civilization - at the very minimum. A recent article calculated that global average temperature increases of $\approx 11-12^{\circ} \mathrm{C}$ would cause conditions under which more than half of today's human population would be living in places where there would be periods (at least once a year) when death from heat stress would ensue after about six hours of exposure. ${ }^{6}$

As noted, the "standard" BCA damages function reduces welfare-equivalent consumption by a quadratic-polynomial multiplier. This essentially describes a single-attribute utility function, or, equivalently, a multi-attribute utility function with strong substitutability between the two attributes of consumption and temperature change. This would be an appropriate formulation if the main impact of climate change is, say, to drive up the price of food and increase the demand for air conditioning. This particular choice of functional form allows the economy to substitute consumption for higher temperatures relatively easily, since the limiting elasticity of substitution between consumption and higher temperatures is one (due to the multiplicative-polynomial assumption). Very different optimal policies can be produced when other functional forms are used to express the disutility of disastrously high temperatures. To take an example, suppose that the disutility of temperature change is additively separable instead of being multiplicatively separable (as in the "standard" BCA). Suppose that welfare is instead the analogous additively-separable arithmetic difference between a CRRA utility function of consumption and a quadratic loss function of temperature changes. This amounts to postulating a genuine multi-attribute utility function that describes a situation where the main impact of climate change is on things that are not readily substitutable with material wealth, such as biodiversity and health. If the coefficient of relative risk aversion on the CRRA utility function of consumption is two, it implies an elasticity of substitution between consumption and temperature change of one half. Empirically, using this additive form - even without any uncertainty - prescribes a significantly more stringent curtailment of GHG emissions than what emerges from the analogous multiplicative form of the "standard" BCA. ${ }^{7}$

\footnotetext{
${ }^{6}$ Sherwood and Huber (2010).

${ }^{7}$ With coefficient of relative risk aversion two, the above additively-separable specification is mathematically equivalent to the constant elasticity of substitution (CES) specification of Sterner and Persson (2008) with elasticity of substitution one half. In their pioneering study, Sterner and Persson showed empirically
} 
The above examples of non-robustness with respect to a damages function for high temperatures, which we cannot know confidently, constitutes my Exhibit 4.

"Exhibit 5" concerns the notorious issue of how to discount the distant future. The effects of global warming and climate change will be spread out over what might be called the "deep future" - centuries and even millennia from now. The logic of compounding a constant positive interest rate forces us to say that what one might conceptualize as monumental even earth-shaking - events like catastrophic climate change, do not much matter when they occur in the deep future. Perhaps yet more disconcerting, when exponential discounting is extended over very long time periods there is a truly extraordinary dependence of BCA on the choice of a discount rate. Seemingly insignificant differences in discount rates can make an enormous difference in the present discounted value of distant-future payoffs. In many long-run situations, almost any answer to a BCA question can be defended by one particular choice or another of a constant discount rate. This is true in general, but it is an especially acute problem when very-distant-future events like climate change (especially catastrophic climate change) are being discounted.

There is a high degree of uncertainty about what should be taken as the appropriate real rate of return on capital in the long run, accompanied by much controversy about its implications for long-run discounting. There is no deep reason or principle that allows us to extrapolate past rates of return on capital into the distant future. The industrial revolution itself began some two centuries ago in Britain, and only slowly thereafter permeated throughout the world. The seeming trendlessness of some past rates of return is a purely empirical reduced-form observation, which is not based on any underlying theory that would confidently allow projecting past numbers far into the future. There are a great many fundamental non-extrapolatable factors, just one example of which is the unknown future rate of technological progress. Even leaving aside the question of how to project future interest rates, additional issues for climate change involve which interest rate to choose out of a multitude of different rates of return that exist in the real world. ${ }^{8}$ Furthermore, there is a strong normative element having to do with what is the "right" rate, which includes an ethical dimension to discounting climate change across many future generations that is difficult to evaluate and incorporate into standard BCA. This normative issue is further complicated when the event impacting future generations is a low-probability high-impact catastrophic outcome.

The constant interest rates used for discounting in the "standard" BCA would be viewed

\footnotetext{
- by plugging it into Nordhaus's deterministic DICE model - that their CES (or, equivalently, my additive) welfare specification prescribes a significantly more aggressive policy response to global warming (with a significantly higher carbon tax) than the analogous multiplicative specification of the "standard" CBA.

${ }^{8}$ For more on this see Weitzman (2007).
} 
by many people as severely biasing BCA toward minimizing into near-nothingness the present discounted value of distant future events, like climate change. This kind of exponential discounting, perhaps more than anything else, makes scientists and the general public suspicious of the economist's "standard" BCA of climate change, since it trivializes even truly enormous distant-future impacts. To be honest, I think that among economists there are but few who do not feel uneasy about evaluating distant-future climate-change impacts this way. One line of research, in which I have been involved, shows that when the discount rate itself is uncertain it implies that the "effective" discount rate declines over time to its lowest possible value. ${ }^{9}$ Empirically, this effect can be quite powerful. ${ }^{10}$ The driving force is a "fear factor" from risk aversion to permanent productivity shocks representing bad future states of the world. Whatever its source, the unknown discount rate for BCA of climate change (and the extraordinary sensitivity of policy to its choice) is yet another big structural uncertainty in the economic analysis of climate change, especially for evaluating possible catastrophes. This is my Exhibit 5.

These five "exhibits" could readily be extended to incorporate yet more examples of structural uncertainty, but enough is enough. To summarize, the economics of climate change consists of a very long chain of tenuous inferences fraught with big uncertainties in every link: beginning with unknown base-case GHG emissions; then compounded by big uncertainties about how available policies and policy levers will transfer into actual GHG emissions; compounded by big uncertainties about how GHG flow emissions accumulate via the carbon cycle into GHG stock concentrations; compounded by big uncertainties about how and when GHG stock concentrations translate into global average temperature changes; compounded by big uncertainties about how global average temperature changes decompose into specific changes in regional weather patterns; compounded by big uncertainties about how adaptations to, and mitigations of, climate-change damages at a regional level are translated into regional utility changes via an appropriate "damages function"; compounded by big uncertainties about how future regional utility changes are aggregated into a worldwide utility function and what should be its overall degree of risk aversion; compounded by big uncertainties about what discount rate should be used to convert everything into expectedpresent-discounted values. The result of this lengthy cascading of big uncertainties is a reduced form of truly extraordinary uncertainty about the aggregate welfare impacts of catastrophic climate change, which mathematically is represented by a PDF that is spread out and heavy with probability in the tails.

What I would wish a reader might take away from these five exhibits is the notion that

\footnotetext{
${ }^{9}$ See Weitzman (1998).

${ }^{10}$ See Weitzman (2010).
} 
the seeming immunity of the "standard" BCA to such stylized facts seems peculiar. An unprecedented and uncontrolled experiment is being performed by subjecting planet Earth to the shock of a geologically-instantaneous injection of massive amounts of GHGs. Yet the standard BCA seems almost impervious to the extraordinarily uncertain probabilities and consequences of catastrophic climate change. A reader should feel intuitively that it goes against the grain of common sense when, in view of the above five exhibits of structural uncertainty, a climate-change BCA does not much depend upon how potential future disasters are modeled and incorporated into the BCA. This uneasy feeling - of a system-wide failure being plausible science fiction that is not adequately represented in the "standard BCA of climate change" - is my opening argument. I turn next to the theory.

\section{The Dismal Theorem, Infinity, and BCA.}

I begin this section by asking why is it relevant in the first place to have any supporting theory at all if the five stylized-fact "exhibits" from last section are convincing. Why aren't these stylized facts alone sufficient evidence that there is a problem with the "standard BCA of climate change"? My answer is that a combined theoretical plus empirical-intuitive argument delivers a particularly powerful one-two punch at the treatment of structural uncertainty in the standard BCA. In this respect I believe that the whole of my argument is bigger than the sum of its two parts. The theoretical part reinforces the empirical part by placing it within a formal mathematical framework. When the intuitive "exhibits" are seen as reflecting some formalized theoretical structure, then it becomes less easy to brush them aside as mere sniping at an established model. In this theoretical section of the paper, as in the last empirical section, I emphasize the intuitive plausibility of the case I am trying to make - here focusing on the underlying logic driving the theory.

The last section argued that it is only common sense that climate-change policy implications should depend on the treatment of low-probability extreme-impact outcomes. In my article (Weitzman (2009)), the main question I attempted to address was whether such intuitive sensitivity is reflecting some deeper principle. My answer was that there is a basic underlying theoretical principle that indeed points in this direction. The logic is simple enough to be grasped intuitively without understanding the fancy math required to state and prove a formal version. In this section I restate the theoretical arguments in what is hopefully a more intuitive form.

Let welfare $W$ stand for expected present discounted utility, whose theoretical upper bound is $B$. Let $D \equiv B-W$ be expected present discounted disutility. Here $D$ stands for

what might be called the "diswelfare" of climate change. Assume for the sake of argument 
that $D$ is "essentially" unbounded in the particular case of climate change because global liability is "essentially" unlimited in a worst-case scenario. (More later on what happens when $D$ is, technically, bounded.) Because the integral over a nonnegative probability measure is one, the PDF of $\ln D$ must decline to zero. In other words, extreme outcomes can happen, but their likelihood diminishes to zero as a function of how extreme the outcome might be. The idea that extreme outcomes cannot be eliminated altogether, but are hypothetically possible with some positive probability, is not at all unique to climate change. Almost nothing in our world has a probability of exactly zero or exactly one. What is worrisome is not the fact that the upper tail of the PDF of $\ln D$ is long (reflecting the fact that a meaningful bound on diswelfare does not exist), but that it might be fat (with probability density). The critical question is how fast does the probability of a catastrophe decline relative to the welfare impact of the catastrophe.

Unless otherwise noted, my default meaning of the term "fat tail" (or "thin tail") ${ }^{11}$ henceforth concerns the upper tail of the $\mathrm{PDF}$ of $\ln D$, resulting from whatever combination of probabilistic temperature changes, temperature-sensitive damages, utility functions, and so forth, by which this comes about. This is the PDF that ultimately matters. Empirically, it is not the fatness of the tail of temperature PDFs alone or the reactivity of the damages function to high temperatures alone, or the degree of relative risk aversion alone, or any other factor alone, that counts, but the interaction of all such factors in determining the upper-tail fatness of the PDF of $\ln D$. For example, other things being equal the PDF of $\ln D$ has a fatter tail the more curved is the utility function or the greater is the probability of low consumption, but neither condition alone implies a fat-tailed PDF of $\ln D$. It may seem arcane, but the upper-tail fatness of the reduced form PDF of $\ln D$ is the core issue in the economics of catastrophic climate change. Of course it is extremely difficult to know the fatness of the upper tail of the PDF of $\ln D$, which is precisely the main point of this paper.

My article indicated a theoretical tendency for the PDF of $\ln D$ to have a fat tail. Conceptually, the underlying mechanism is not difficult to grasp. Structural uncertainty essentially means that the probabilities are unsure. A formal Bayesian translation might be that the structural parameters of the relevant PDFs are themselves uncertain and have their own

\footnotetext{
${ }^{11}$ There is some wiggle room in the definition of what constitutes a fat-tailed PDF or a thin-tailed PDF, but everyone agrees that probabilities declining exponentially or faster (like the Normal) are thin tailed, while probabilities declining polynomially or slower (like the Pareto) are fat tailed. The standard example of a fat-tailed PDF is the power law (aka Pareto aka inverted polynomial) distribution, although, for example, a Student- $t$ or inverted-gamma PDF is also fat-tailed. A normal or a gamma are examples of thin-tailed PDFs, as is any PDF having finite supports, like a uniform distribution or a discrete-point finite distribution. Although both PDFs must approach a limit of zero, the ratio of a fat-tailed probability divided by a thintailed probability goes to infinity in the limit.
} 
PDFs. The article expressed this idea in a formal argument that the reduced form "posterior predictive" PDF (in Bayesian jargon) of $\ln D$ tends to be fat tailed because the structural parameters are unknown. Loosely speaking, the driving mechanism is that the operation of taking "expectations of expectations" or "probability distributions of probability distributions" tends to spread apart and fatten the tails of the compounded posterior-predictive PDF. From past samples alone, it is inherently difficult to learn enough about the probabilities of extreme future events to thin down the bad tail of the PDF, because we don't have much data about analogous past extreme events. This mechanism provides at least some kind of a generic story about why fat tails might be inherent in some situations.

The part of the distribution of possible future outcomes that we might now know (from inductive information of a form as if conveyed by past data) concerns the relatively more likely outcomes in the middle of the distribution. From past observations, plausible interpolations or extrapolations, and the law of large numbers, there may be at least some modicum of confidence in being able to construct a reasonable picture of the central regions of the posterior-predictive PDF. As we move towards probabilities in the periphery of the distribution, however, we are increasingly moving into the unknown territory of subjective uncertainty, where our probability estimates of the probability distributions themselves become increasingly diffuse because the frequencies of rare events in the tails cannot be pinned down by previous experiences. It is not possible to know enough now, from past data alone, about the frequencies of future extreme tail events to make the outcomes of a BCA be independent from artificially-imposed limitations on the extent of possibly ruinous disasters. Climate-change economics generally, and the fatness of climate-change tails specifically, are prototypical examples of this principle, because we are trying to extrapolate inductive knowledge far outside the range of limited past experience. To put a sharp point on this seemingly abstract issue, the thin-tailed PDFs implicitly supporting gradualist conclusions have at least some theoretical tendency to morph into fat-tailed PDFs when it is admitted that we are unsure about the functional forms or structural parameters behind these implicitly assumed thin-tailed PDFs - at least where high temperatures are concerned.

A fat upper tail of the PDF of $\ln D$ makes the willingness to pay (WTP) to avoid extreme climate changes very large, indeed arbitrarily large if the coefficient of relative risk aversion is bounded above one. The article gave a formal argument within a specific mathematical structure, but this formal argument could have been embedded in alternative mathematical structures - with the same basic message. The particular formal argument I gave in the article came in the form of what I called a "dismal theorem" (DT). In this particular formalization, the limiting expected stochastic discount factor is infinite (or, what I take to be equivalent for purposes here, the limiting WTP to avoid fat-tailed disasters constitutes all 
of output). Of course, real-world WTPs are not $100 \%$ of output. Presumably the PDF in the bad fat tail is thinned, or even truncated, perhaps from considerations akin to what lies behind the value of a statistical life (VSL) - after all, we would not pay an infinite amount to eliminate the fat upper tail of climate-change catastrophes. Alas, in whatever way the bad fat tail is thinned or truncated, a climate-change BCA based upon it might remain sensitive to the details of the thinning or truncation mechanism, because the disutility of extreme climate change is "essentially" unbounded. (There is "essentially" unlimited liability here because global stakeholders cannot short the planet as a hedge against catastrophic climate change.) Later I discuss the meaning of this potential lack of robustness in climatechange BCA and speculate on some actionable consequences it might imply regarding what economists do and say.

Disagreements abound concerning how to interpret the infinity symbol that appears in the formulation of DT. There is a natural tendency to scoff at economic models that yield infinite outcomes. This reaction is presumably inspired by the idea that infinity is a ridiculous result; therefore any model that has an infinity symbol in it is fundamentally misspecified, and thus dismissable. Critics argue earnestly from their favorite examples that expected disutility from climate change cannot actually be infinite, as if this were a telling indictment of the entire fat-tailed methodology. I believe that, in the particular case of climate change, the infinity is trying to tell us something important. The infinite limit in DT is a formal mathematical way of saying that structural uncertainty in the form of fat tails is, at least in theory, capable of swamping the outcome of any BCA that disregards this aspect.

The key issue here is not a mathematically illegitimate use of an infinite limit in DT. Infinity is a side-show that has unfortunately diverted attention from the main issue. It is easy to modify utility functions, to add on VSL-like restrictions, to truncate probability distributions arbitrarily, or to introduce ad hoc priors that cut off or otherwise severely dampen low values of welfare-equivalent consumption. Introducing any of these (or many other attenuating mechanisms) formally replaces the infinity symbol by some uncomfortably large, but finite, number. Unfortunately, removing the infinite limit in these or other ways does not eliminate the underlying problem because it then comes back to haunt in the form of a WTP to erase the structural uncertainty that is arbitrarily large. How large depends sensitively upon obscure details about how the upper tail of the PDF of $\ln D$ has been thinned or bounded. One can easily remove the infinity symbol from DT, but one cannot so easily "remove" the underlying substantive economic problem of extreme sensitivity to fat tails and the resulting conundrum of deciding policy under such circumstances. The overwhelming majority of real-world BCAs have thin upper tails in $\ln D$ from limited exposure to system-wide catastrophic risk. However, a few very important real-world situations 
have effectively unlimited exposure due to structural uncertainty about their potentially open-ended catastrophic reach. Climate change is unusual in potentially affecting the entire worldwide portfolio of utility by threatening to drive all of planetary welfare to disastrously low levels in the most extreme scenarios.

The "standard" BCA approach appears to offer a constructive ongoing scientific-economic research program for generating ever more precise outputs from ever more precise inputs. By contrast, my main message can seem off-putting because it can be painted as anti-scientific and anti-economic. Fat tails and the implied limitations that prevent BCA from reaching robust conclusions are frustrating for economists. After all, we make a living from plugging rough numbers into simple models and reaching specific conclusions (more or less) on the basis of these numbers. What are we supposed to advise policy makers and politicians quantitatively about how much effort to spend on averting climate change if conclusions from modeling fat-tailed uncertainties are not clear-cut? Practical men and women of action have a low tolerance for vagueness and crave some kind of an answer, so they have little place for even a whiff of fuzziness from two-handed economists. It is threatening for us economists to admit that constructive "can do" climate-change BCA may be up against some limitations on the ability of quantitative analysis to give robust policy advice. But if this is the way things are with the economics of climate change, then this is the way things are. Non-robustness to subjective assumptions about catastrophic outcomes is an inconvenient truth to be lived with rather than a fact to be denied or evaded just because it looks less scientifically objective in BCA. If this limits the ability to give fine-grained answers to an impatient public, then so be it.

In my opinion, economists need to emphasize more openly to the policy makers, the politicians, and the public that, while formal climate-change BCA may be helpful, there is a danger of possible overconfidence from undue reliance on subjective judgements about the probabilities and welfare impacts of extreme events. What we can do constructively as economists is to explain better the magnitudes of the unprecedented structural uncertainties that are involved, explain why this feature limits what we can say, and present the best BCAs and the most honest sensitivity analyses that we can under fat-tailed circumstances, including many different functional forms for extremes. At the end of the day, policy makers must decide what to do on the basis of an admittedly sketchy economic analysis of a gray area that just cannot be forced to render clear robust answers. The moral of the dismal theorem is that, under extreme tail uncertainty, seemingly casual decisions about functional forms, parameter values, and tail fatness can dominate BCA. Economists should not pursue a narrow, superficially crisp, analysis by blowing away the low-probability highimpact catastrophic scenarios as if this is a necessary price we must pay for the worthy goal 
of giving answers and advice to policy makers. An artificial infatuation with crispness is likely to make our analyses go seriously askew and undermine the credibility of what we have to offer by effectively marginalizing the very possibilities that make climate change so grave in the first place.

The issue of how to deal with the deep structural uncertainties in climate change would be completely different and immensely simpler if systemic inertias, like the time required for the system to naturally remove extra atmospheric $\mathrm{CO}_{2}$, were short, as is the case for many airborne pollutants like ozone, sulfur dioxide, and particulates. Then an important component of an optimal strategy might be along the lines of "wait and see." With strong reversibility, an optimal climate-change policy should logically involve (among other elements) waiting to learn how far out on the bad fat tail the planet will end up, followed by midcourse corrections if we seem to be headed for a disaster. Alas, the problem of climate change seems bedeviled almost everywhere by significant stock-accumulation inertias - in atmospheric $\mathrm{CO}_{2}$, in the absorption of heat or $\mathrm{CO}_{2}$ by the oceans, and in many other relevant physical and biological processes - that are slow to respond to attempts at reversal.

Take atmospheric carbon dioxide as one specific example. Solomon et al (2009) calculated how concentrations of $\mathrm{CO}_{2}$ would be expected to fall off over time if all anthropogenic emissions were to cease immediately, following a future $2 \%$ annual growth rate of emissions up to peak concentrations of 450,550,650,750, 850 and 1,200 ppm. As the authors state: "The example of a sudden cessation of emissions provides an upper bound to how much reversibility is possible, if, for example, unexpectedly damaging climate changes were to be observed." Results differed for different trajectories and scenarios, but a crude rule of thumb seemed to be that approximately $70 \%$ of the peak enhancement level over the preindustrial level of $280 \mathrm{ppm}$ persevered after 100 years of zero emissions, while approximately $40 \%$ of the peak enhancement level over the preindustrial level of $280 \mathrm{ppm}$ persevered after 1,000 years of zero emissions. This means, for example, that if atmospheric $\mathrm{CO}_{2}$ concentrations were to peak at $800 \mathrm{ppm}$, followed forever thereafter by zero emissions, then atmospheric concentrations would be $\approx 650 \mathrm{ppm}$ after 100 years and $\approx 500 \mathrm{ppm}$ after 1,000 years. These numbers do not look to me like evidence supporting "wait and see" policies. The capacity of the oceans to take up atmospheric heat, and many, many other relevant mechanisms, tell a similar story of long stock-accumulation irreversibilities relative to the time it takes to extract and act upon meaningful signals of impending disasters.

Many researchers promote alternative specifications that do not imply nearly such extreme outcomes as do my specifications. I do not claim that their formulations are wrong or even implausible. I merely point out that they are not likely to be robust with respect to assumptions about extreme catastrophic climate change and that they therefore fail an 
important "stress test." Of course the reader should weigh the plausibility of the arguments and the reasonableness of the various specifications on their own merits. But it is difficult to form opinions about probabilities of climate-change extremes, or about disutility functions for extreme temperatures, or about lots of other relevant things for deciding the tail fatness of the PDF of $\ln D$. Suppose, for the sake of argument, that a policy maker believes the probability is $50 \%$ that my fat-tailed specification is correct and $50 \%$ that the thin-tailed specification of someone else is correct. Then, other things being equal, rational policy should lean more in the direction of my fat-tailed conclusions than in the direction of someone else's thin-tailed conclusions because of the highly asymmetric consequences of fat tails vs. thin tails. In this sense, whether it is fair or unfair, the playing field is not level between me and someone else. If one person advises you that a fire insurance policy protecting your house against extreme losses is unnecessary because so few houses of your kind burn to the ground, while another person advises you that a complete fire insurance policy is necessary in your case, other things being equal should you flip a coin in deciding what to do just because both advisers seem to be giving equally credible guidance?

Climate change is not the only possible catastrophic threat to humanity. In my article I listed what I consider to be the half-dozen or so serious contenders with climate change for potentially catastrophic impacts with non-negligible probabilities: biotechnology, nanotechnology, asteroids, strangelets, pandemics, runaway rogue computers, nuclear proliferation and went on to give a few tentative reasons why I think that climate change is especially worrisome. It may well be that each of the other half-dozen or so serious candidates for fattailed disasters deserves its own ballpark estimate of tail probabilities along with extremely crude calculations of policy implications, which is about the best we can do with potential catastrophes. Even if this were true, however, it would not lessen the need to reckon with the strong potential implications of fat tails for BCA-like calculations in the particular case of climate change.

\section{Concluding Comments}

Taking fat tails into account has implications for climate-change policy. Qualitatively, fat tails favor more aggressive policies to lower GHGs than the "standard" BCA. Alas, the quantitative implications are less clear. As this paper has stressed, the natural consequence

of fat-tailed uncertainty should be to make economists less confident about climate-change BCA and to make them adopt a more modest tone that befits less robust policy advice. My own conclusion is that the sheer magnitude of the deep structural uncertainties concerning catastrophic outcomes, and the way we express this in our models, is likely to influence 
plausible applications of BCA to the economics of climate change now and for some time to come.

\section{References}

[1] Archer, David. Global Warming. Blackwell Publishing, 2007.

[2] Dieter Lüthi, Martine Le Floch, Bernhard Bereiter, Thomas Blunier, Jean-Marc Barnola, Urs Siegenthaler, Dominique Raynaud, Jean Jouzel, Hubertus Fischer, Kenji Kawamura \& Thomas F. Stocker. "High-resolution carbon dioxide concentration record 650,000-800,000 years before present." Nature, 453, 379-382 (15 May, 2008).

[3] IPCC-AR4. Climate Change 2007: The Physical Science Basis. Contribution of Working Group I to the Fourth Assessment Report of the Intergovernmental Panel on Climate Change. Cambridge University Press, 2007 (available online at http://www.ipcc.ch).

[4] Nordhaus, William. A Question of Balance. Yale University Press, 2008.

[5] Natalia Shakhova, Igor Semiletov,Anatoly Salyuk, Vladimir Yusupov, Denis Kosmach, Örjan Gustafsson. "Extensive Methane Venting to the Atmosphere from Sediments of the East Siberian Arctic Shelf." Science, 327, 5970, pp. 1246 - 1250.

[6] Sherwood, Steven C. and Matthew Huber. "An adaptability limit to climate change due to heat stress." forthcoming in 2010 Proceedings of the National Academy of Sciences.

[7] Solomon, Susan, Gian-Kasper Plattner, Reto Knutti, and Pierre Friedlingststein (2009). "Irreversible climate change due to carbon dioxide emissions." Proceedings of the $\mathrm{Na}$ tional Academy of Sciences 106 (6): 1704-1709.

[8] Sterner, Thomas, and U. Martin Persson. "An Even Sterner Review: Introducing Relative Prices into the Discounting Debate." Review of Environmental Economics and Policy, 2008 (Winter), 2(1), pp. 61-76.

[9] Weitzman, Martin L. "Why the Far-Distant Future Should Be Discounted at Its Lowest Possible Rate." Journal of Environmental Economics and Management 36 (3): 201-208 (1998).

[10] Weitzman, Martin L. "The Stern Review of the Economics of Climate Change." Journal of Economic Literature, 45 (3), 703-724, (2007). 
[11] Weitzman, Martin L. "On Modeling and Interpreting the Economics of Catastrophic Climate Change." Review of Economics and Statistics, 91 (1): 1-19 ( February 2009).

[12] Weitzman, Martin L. "Risk-Adjusted Gamma Discounting." Journal of Environmental Economics and Management. July 2010. 